\title{
Coulisses
}

Revue de théâtre

14 | Printemps 1996

Varia

\section{Les Métamorphoses de Lulu}

Gisèle G. Holtzer

\section{OpenEdition}

Journals

Édition électronique

URL : http://journals.openedition.org/coulisses/4667

DOI : $10.4000 /$ coulisses.4667

ISSN : 2546-9460

\section{Éditeur}

Presses universitaires de Franche-Comté

\section{Édition imprimée}

Date de publication : 1 mai 1996

Pagination : 49-50

ISSN : 1150-594X

\section{Référence électronique}

Gisèle G. Holtzer, « Les Métamorphoses de Lulu », Coulisses [En ligne], 14 | Printemps 1996, mis en ligne le 20 mars 2019, consulté le 23 octobre 2019. URL : http://journals.openedition.org/coulisses/ 4667 ; DOI : 10.4000/coulisses. 4667

Ce document a été généré automatiquement le 23 octobre 2019

Coulisses 


\title{
Les Métamorphoses de Lulu
}

\author{
Gisèle G. Holtzer
}

1 Lulu est l'une des grandes figures mythiques de la création artistique, imaginée par le dramaturge allemand Frank Wedekind, immortalisée au cinéma en 1921 par Georg Wilhelm Pabst, à l'opéra par Alban Berg'. La pièce présentée sous le titre Lulu est la réunion de deux drames de Wedekind, L'Esprit de la terre (Erdgeist) publié en 1895 qui retrace l'ascension sociale de Lulu jusqu'à la mort de son quatrième mari, le docteur Schoen et La Boite de Pandore (Die Büchse der Pandora), « tragédie de monstres » éditée en 1904, consacrée à la déchéance et à la mort de l'héroïne.

Lulu est cet esprit de la terre, force élémentaire de la nature que Wedekind définit ainsi: "Lulu n'est pas un personnage réel mais la personnification de la sexualité primitive qui provoque le mal sans en avoir conscience ». La mission de Lulu, « créature sans âme ", est clairement exprimée dans le Prologue de la pièce: "Elle a été créée pour faire le malheur, pour attirer, séduire, pour empoisonner - et pour tuer - sans jamais laisser une trace $»^{2}$.

Dans la mise en scène présentée à l'Athénée début 1996, différents rôles sont joués par les mêmes comédiens : Schigolch-Goll, Schoen-Jack l'Eventreur. L'idée initiale semble appartenir à A. Berg. Dans son opéra, en effet, les mêmes chanteurs incarnent à la fois les victimes de Lulu et ses clients du dernier acte ; on a les correspondances

- le professeur de médecine (Goll chez Wedekind) - le professeur

- le peintre (Schwartz chez Wedekind) - le nègre

- Schoen - Jack l'Eventreur.

3 Berg donne ainsi à son opéra une forte unité dramatique fondée sur un fil interprétatif qui relie les deux parties de l'œuvre : l'ascension de Lulu / sa déchéance finale. 


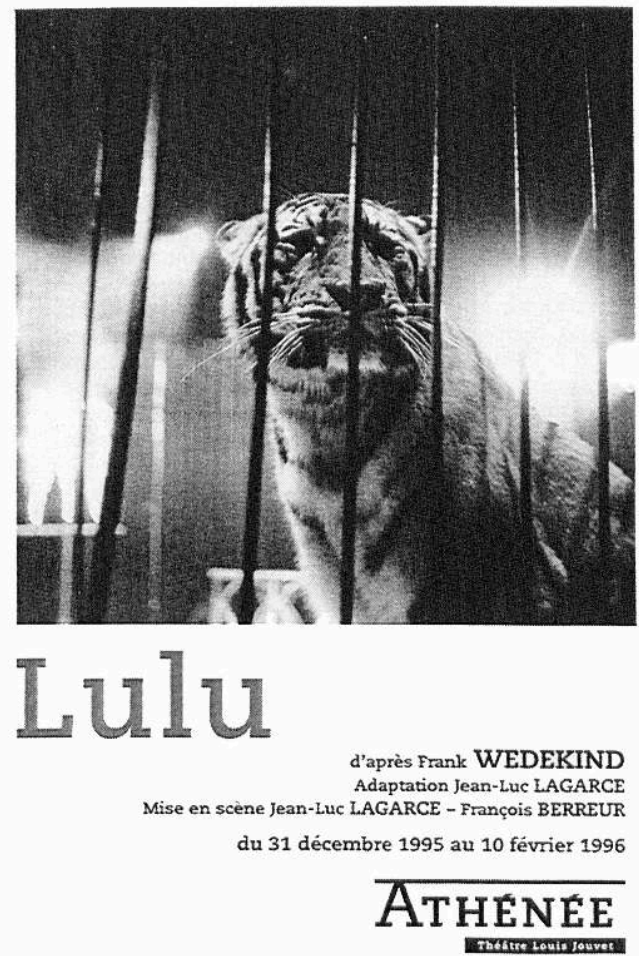

4 Le dernier acte est chez Berg "le grand châtiment ", la revanche du monde des hommes qui, après avoir été détruits par Lulu, se vengent à la fin en la dégradant par la prostitution et en la tuant. On voit ce que de telles connexions, non indiquées chez Wedekind, apportent à la signification symbolique de l'œuvre. L'idée est reprise et adaptée dans la mise en scène de Lulu. La correspondance Schoen-Jack l'Eventreur (Schoen tué par Lulu, elle-même victime de Jack l'Eventreur), explicitement manifestée dans l'opéra de Berg et dans la version de Jean-Luc Lagarce, est le support d'intéressants réseaux de significations.

La relation Lulu-Jack l'Eventreur est également sous-tendue par un parallélisme symbolique. Pour les deux personnages, la possession sexuelle implique l'anéantissement de l'autre, déchéance morale pour les victimes masculines de Lulu, mort pour les victimes féminines de Jack l'Eventreur. W. Pabst est sans doute un de ceux qui a le mieux traduit le lien profond entre les deux personnages.

A la violence expressionniste de Wedekind où la fin de la pièce explose dans le sang, la fureur et la mort, Pabst substitue une fin douce et terrible : «Je te frapperai sans colère et sans haine, comme un boucher » dit Jack à Lulu dont la mort est signifiée par l'image de la main s'ouvrant lentement au fur et à mesure que sa vie s'échappe. Louise Brooks, interprète de Lulu dans le film, donne un témoignage très significatif sur la valeur d'accomplissement qu'est pour Lulu sa mort finale : «C'est la veille de Noël, et elle est sur le point de recevoir le cadeau dont elle a toujours rêvé depuis son enfance : mourir de la main d'un maniaque sexuel $»^{3}$.

Dans la mise en scène de Lulu par Jean-Luc Lagarce et François Berreur, un décor unique sert de cadre aux multiples lieux de l'action (atelier du peintre, salon de Lulu, chambre sous les toits à Londres...), les modifications d'ambiance (jeux de lumière), la présence d'objets (chevalet $\mathrm{du}$ peintre, table de maquillage...) indiquant les 
changements de lieux. Un immense canapé aux formes étranges, un peu sinueuses comme le serpent qui symbolise Lulu ${ }^{4}$, occupe le centre de l'espace scénique. L'unité du cadre permet une mise en scène au rythme plus nerveux, un enchaînement fluide de l'action et un resserrement autour des personnages qui, quel que soit le lieu, sont toujours dans le même « zoo ", dans la même « ménagerie ».

8 L'espace unique contraste avec la prolixité des didascalies de la pièce de Wedekind détaillant les éléments du décor. Le tableau IV prévoit ainsi « Une salle somptueuse en Renaissance allemande au plafond de chêne sculpté, avec boiseries et tapisseries. En haut une galerie à colonnes et rideaux; de la galerie un escalier massif descend jusqu'au milieu de la scène. A droite une cheminée, plus loin une fenêtre à rideaux. A gauche une portière cache une porte $»^{5}$.

9 L'interprète du rôle titre, Lulu un peu androgyne, propose une image qui diffère très sensiblement de la Lulu de notre imaginaire culturel habité par le large regard enfantin de Louise Brooks sous sa frange noire. A-t-elle pour le spectateur la force d'attraction, le mystère vénéneux et limpide de la bête "terrible » et "merveilleuse ", la " douce " et "féroce» bête dont parle le texte? La réponse variera à la mesure des représentations secrètes de chacun. Mais que nous dit Lulu en cette fin de siècle ? La critique de l'hypocrisie de la société au temps de Wedekind a perdu de sa pertinence, la défense de la liberté de la femme dans le domaine du sexe semble un combat d'un autre temps. Ce n'est manifestement pas ce qui intéresse le metteur en scène contemporain. Restent (peut-être) les interrogations sur l'amour (et son absence) et la mort, la difficile quête de l'autre et de soi dans un monde sans âme, sans culpabilité ni compassion.

\section{NOTES}

1. Alban Berg est mort en 1935 sans avoir pu achever son œuvre (orchestration de l'acte III non terminée). La première mondiale aura lieu à Zurich le 2 juin 1937 dans sa version incomplète et il faudra attendre 1979 pour voir la première représentation de Lulu dans son intégralité (dans une version d'exécution de l'acte III réalisée par Friedrich Cerha qui y travailla de 1962 à 1974), à l'Opéra de Paris, sous la direction de Pierre Boulez.

2. Le texte de référence est la version du Prologue dans l'adaptation de Jean-Luc Lagarce. Créée à Paris, Lulu a été jouée au théâtre de l'Athénée du 8 janvier au 10 février 1996 et représentée au Théâtre Granit de Belfort le 17 mars 1996.

3. Louise Brooks, Louise Brooks, Paris, Ed. Pvgmalion, p. 189. Ouvrage traduit de Lulu in Hollywood, 1982.

4. Dans le Prologue, à la demande du Dompteur « Apporte-moi d'abord notre serpent ", l'acteur qui joue Schigolch amène Lulu sur le devant de la scène.

5. Extrait de la version française et adaptation par Pierre Jean Jouve de Lulu de Wedekind, L'Age d'Homme / Théâtre vivant, 1969, p. 93. 